\title{
Nota sobre o encontro de casos autóctones de malária vivax por meio de técnica sorológica, em São Paulo
}

* Superintendência de Controle de Endemias (SUCEN) da Secretaria de Estado da Saúde de São Paulo

\author{
Maria.Esther de Carvalho* \\ Carmem Moreno Glasser* \\ Lucilia A parecida dos Santos* \\ Ricardo Mário de Carvalho Ciaravolo*
}

A descoberta de infecções assintomáticas, oligossintomáticas ou subpatentes em casos de malária em populações humanas pode decorrer, atualmente, da interpretação de resultados de reações sorológicas.

Para a análise da infecção em tais áreas, utilizam-se reações de imunofluorescência indireta (RIFI), em uso na SUCEN há algum tempo, para diagnóstico de infecção chagásica, com simplificações in troduzidas por Ferreira \& Carvalho $^{1}$. Tais simplificações foram incluídas na técnica para malária recomendada pela Organização Mundial da Saúde, $\mathrm{OMS}^{4}$.

As reações de imunofluorescência indireta foram realizadas com antígeno de Plasmodium vivax, preparado segundo a técnica indicada por López-Antuñano ${ }^{3}$. Foram usados conjugados antigamaglobulinas humanas totais e IgM, adquiridos comercialmente e padronizados no Laboratório de Sorologia da SUCEN. A leitura das reações foi feita usandose microscópio binocular projetado para esse fim, marca "Olympus". A fonte de radiação, neste caso, é lâmpada de vapor de mercúrio de alta pressão, tipo HBO-200W/4. Os habituais controles positivos e negativos foram incluídos em todos os conjuntos de reações realizadas em uma sessão.

As amostras a analisar foram colhidas por meio de punção da polpa digital e absorvidas em papel-filtro "Whatman" n? 3. A quantidade de sangue contida em unidade de área de papel foi determinada de acordo com o método proposto por Ferreira \& Carvalho ${ }^{2}$.

A hemoscopia consistiu no exame de gotas espessas de sangue colhido de polpa digital, coradas segundo a técnica de Romanowski, modificada de acordo com as prescrições da Organização Pan-Americana da Saúde ${ }^{5}$.

A deteç̧ão do primeiro caso resultou de solicitação de esclarecimento relacionada com caso não-conclusivo, após hemoscopias reiteradas. Os dois outros surgiram de estudos sorológicos realizados em população rural de localidades do município de Peruípe (microrregião da Baixada Santista), região onde se estavam registrando casos autóctones de ma- 
lária com freqüência superior à esperada. Deve ser assinalado que o segundo caso confirmado pela hemoscopia foi encontrado após o processamento de 439 amostras (pela RIFI) da população e o terceiro após 1.902 amostras. Casos como estes correspondem ao limiar de sensibilidade da hemoscopia segundo a técnica da gota espessa. Assim, a RIFI representa um meio útil para a descoberta de casos assintomáticos, sendo mais um recurso para a avaliação e ulterior controle do problema da transmissão da malária.

\section{DADOS SOBRE OS CASOS (Ordem cronológica)}

19) M.G.D., 57 anos, sexo feminino, residente no Sítio Serra, Município de Iporanga (microrregião Apiaí). A hemoscopia, feita durante atividade normal de LIC (Lâmina de Investigação de Caso) em notificantes de um caso detectado nessa localidade, realizada em 10.04.84, revelou uma única estrutura identificada como $P$. vivax. Em 12.04.84 realizou-se a investigação epidemiológica do caso, e colheram-se amostras de sangue em papelfiltro para realização de RIFI e nova hemoscopia, esta última revelando-se negativa. A RIFI foi realizada em 25.04.84, tendo-se observado título 512 com antígeno de $P$. vivax (Ig total), mostrando-se não-reagente para IgM. No dia 27.04.84 realizou-se nova investigação, com colheita de sangue para hemoscopia (duas gotas espessas). Em apenas uma delas constatou-se a presença de parasitas (densidade equivalente a cerca de 40 parasitas por 100 campos microscópicos). Não foram encontrados parasitas na outra gota. $\mathrm{Na}$ investigação a paciente relatou febrícula, dor de cabeça, calafrios, desde o dia 14.04.84.

2.) A.M.B., 38 anos, sexo masculino, residente em Aldeia dos Indios, município de Peruíbe. Durante palestra educativa visando ao preparo da população para inquérito sorológico a ser desenvolvido na área, em 27.06.84, o paciente ofereceu-se para colheita de sangue, declarando estar febril. Nessa oportunidade, a RIFI revelou título 64 para Ig total e não reagente para IgM, e a hemoscopia foi negativa. Na semana seguinte, em 06.07.84, ao início do tratamento radical para $P$. vivax, baseado no resultado da prova sorológica, colheram-se mais duas gotas de sangue para hemoscopia. Em apenas uma das gotas foram encontrados parasitas, em baixa densidade.

39) C.S.S., 14 anos, sexo masculino, residente em São Francisco II, município de Peruíbe. Colhida em 17.07.84, durante a realização de inquérito sorológico na área, a amostra chegou ao laboratório em 30.07.84. Processa- 
da em 12.08.84, mostrou-se reagente para $P$. vivax, com o título 256 para Ig total e 128 para IgM. No dia 13.08.84, deu-se início ao tratamento radical para $P$. vivax, e a amostra colhida nessa ocasião para hemoscopia revelou densidade de cerca de 40 parasitas por 100 campos microscópicos. A investigação do caso revelou tratar-se de paciente assintomático, cujos resultados de hemoscopias anteriores haviam sido negativos.

Agradecimento: Ao Dr. José Aluisio Bittencourt da Fonseca, Assistente de Gabinete da Superintendência da SUCEN, pela revisão crítica do manuscrito.

\section{REFERENCIAS BIBLIOGRÁFICAS}

1. FERREIRA, C.S. \& CARVALHO, M.E. de. Reações de imunofluorescência: algumas simplificaçð̃es de sua técnica. R. Saúde Pübl., 7 :303-6, 1973.

2. FERREIRA, C.S., \& CARVALHO, M.E. Padronização de papel filtro como suporte de material para reações sorológicas. Rev. bras. Malariol. D. trop., 34 :82-6, 1982.

3. LOPEZ-ANTUÑANO, F.J. Orientaciones sobre la prueba de inmunofluorescencia indirecta para el serodiagnóstico de malaria. San José, Costa Rica, Ministerio de la Salud, 1975. 2p. (mimeo).

4. ORGANIZAÇÃO MUNDIAL DA SAƯDE. Serological testing in malaria. Bull. WHO, $50: 527.35,1974$.

5. ORGANIZAÇÃO PAN-AMERICANA DA SAÚDE. Ma. nual de diagnóstico microscópico da malária. 4.ed. Washington, 1975. 109 p. (Publicação Científica, 176). 